\title{
Information technology and infectious diseases: Promise and pitfalls
}

\author{
A Mark Joffe MD FRCPC
}

E MR, EHR, VAX, PACS, HIT, CIS, CPOE, DSS, IT, CDSS... The lexicon of modern medicine has become a zoo of mysterious acronyms. Hardly a day goes by where I am not bombarded with some new abbreviation that I must add to my nearly maxed-out cerebral hard drive. And, to make matters worse, to access all this new information technology (IT), I have an increasingly large number of logon names and passwords that I am also expected to remember, all needing to be changed at variable intervals. I loathe having to come up with a unique, never before used password that is acceptable to the virtual gods of cyberspace. I am told that this is all in the name of improved and safer health care.

It has been nearly 10 years since the landmark paper of Evans et al (1), published in the New England Journal of Medicine, described the use of computer-assisted management in the care of patients in the intensive care unit at LDS Hospital (Utah, USA). These authors demonstrated improved antibiotic selection and prescribing, with reduction in costs in the critical care setting (1). I thought that clinical decision support systems (CDSS) had hit prime time, and that we would see an explosion in the introduction of such technology. What has happened since and where are we with health IT (HIT)?

At the Association of Medical Microbiology and Infectious Disease Canada - Canadian Association for Clinical Microbiology and Infectious Diseases (AMMI - CACMID) 2007 Annual Conference in Halifax, Nova Scotia, a plenary symposium was devoted to this topic. Three presentations considered different aspects of this issue. First, $\mathrm{Mr} \mathrm{Tim}$ Beasley, the Program Director of Public Health Surveillance, Canada Health Infoway, discussed national initiatives in HIT and the role of Infoway in guiding developments in this area. Infoway is an independent organization comprised of the 14 federal, provincial and territorial deputy ministers of health. Its mission is to act as a "catalyst for collaborative change to accelerate the use of electronic health information systems..." (2). A significant endowment was established to coordinate efforts nationally in the development of electronic health records (EHRs) to better serve the health of
Canadians. Traditional paper-based models with incomplete information, illegible handwriting, a lack of adherence with evidence-based screening and therapeutic guidelines, and incidents of communication breakdown impacting care at multiple levels are viewed as unacceptable as we move forward in the 21 st century. Infoway's role is to provide leadership and expertise while investing with partners to spur development of electronic medical records and EHR deployment across the country.

Dr Shamir Mukhi of the Public Health Agency of Canada discussed the potential for this emerging infostructure to assist in communicable disease surveillance and management, an area of obvious interest to the infectious diseases and medical microbiology community. The Canadian Network for Public Health Intelligence has been established to develop panCanadian strategies for data sharing and analysis, communication, coordination and collaboration for the betterment of the health of Canadians.

Finally, Dr Steven Burdette of the Wright State University Boonshoft School of Medicine (USA) provided a very practical overview of some electronic tools that are available today to assist in the daily practice of infectious diseases and medical microbiology. A riveting live demonstration of many of these tools and how they may be integrated into daily life to improve efficiency and effectiveness was provided.

How far have we come and where are we now in IT? Have the exciting prospects highlighted in Dr Evan's 1998 paper been realized? Manuscripts of Dr Mukhi's and Dr Burdette's talks are included in this issue of the Journal and provide some insights. Dr Burdette provides numerous suggestions and specific tools that are available today and can be readily employed using inexpensive technology that many of us are already using (at least in part). Dr Mukhi offers an exciting roadmap of where we may be able to head in the near future. The promise is indeed there but what have we achieved?

Medicine is increasingly complex, as we are all aware, and we have long since passed the point where it is possible to stay on top of all things for all patients. This may be particularly true in primary care, but also applies to the care of our patient 
population with chronic infectious diseases. Have we ensured that every patient with HIV has received their vaccinations, their lipid and glucose monitoring, and their antiretroviralspecific toxicity monitoring? Should an anal Pap smear be offered to HIV-positive men who have sex with men? Have we provided guidance on smoking cessation and harm reduction? Is our patient with chronic hepatitis B (3) or cirrhotic hepatitis C offered hepatoma monitoring? An EHR with patient-specific prompts could help ensure that individual care is optimized.

While there is considerable promise in improving quality of care, adherence to guidelines and reduction in errors, EHRs have not been consistently demonstrated to do so. Indeed, a recent study (4) of EHRs in the ambulatory care setting confirmed that performance for most quality indicators was suboptimal and the implementation of EHRs was not associated with better quality care.

Two recent systematic reviews of the HIT literature shed further light on the challenges ahead. Of 97 studies utilizing CDSS, approximately two-thirds demonstrated improved practitioner performance, mostly in the areas of diagnostics, preventive care, chronic disease management, drug dosing and prescribing. While most CDSS demonstrated improved performance, one-third did not. In addition, only seven of 52 (13\%) studies demonstrated that CDSS improve patient outcomes (5). More sobering is the reality highlighted in the second review (6) that the majority of studies demonstrating that HIT can improve quality and efficiency are derived from four benchmark institutions utilizing home-grown systems, including the LDS Hospital in the Evans et al study. Moreover, evaluation of these systems has often been conducted by the developers of the system, an important potential source of bias. Thus, generalizability of findings from studies conducted in these benchmark institutions remains questionable. It is likely that there are fundamental differences between these four institutions and others, most notably the interest and commitment of physicians in their own internally developed systems which were likely geared to local issues and responsive to local needs and input. Thus, these institutions and their earlyadopting faculty are likely fundamentally different from other settings in which clinicians are being dragged kicking and screaming into the IT era. It is the difference between 'buy in' and 'force in'.

Introduction of IT into the complex health care work environment is often fraught with frustration and, ultimately, failure. The clinical workplace has been described as a complex sociotechnical system in which people, technology and organizational routines interact in dynamic fashion (7). Failure to consider the dynamics and complexity involved frequently leads to failed attempts to introduce clinical information systems, even in settings in which medical staff are keen and enthusiastic to embrace the new technology. Lapointe and Rivard (8) described attempts to introduce such systems into three Canadian hospital settings leading to dismal failure in two. In one of these failed attempts, significant change in workflow with computerized physician order entry increased physician workload by $1 \mathrm{~h} /$ day to $1.5 \mathrm{~h} /$ day! Little wonder it failed. Physicians are generally quick to adopt new technology, but successful implementation of HIT into the workplace will require careful consideration of interface, usability and integration into normal workflow. Change is difficult, and clinical and intellectual inertia is high. Yet, technology that works, improves efficiency, and enhances work satisfaction and patient care will ultimately be adopted and will be successful (9).

In the practice of infectious diseases, computerized patient records linked to hospital and laboratory information systems, coupled with computer-based CDSS have the potential to assist with differential diagnosis and in choosing appropriate therapy while minimizing antimicrobial resistance, adverse effects and costs (10). However, while we anticipate that such technological solutions should work and should make things better, unintended consequences have occasionally followed implementation. For example, a widely used computerized physician order entry system was noted to facilitate 22 types of medication errors (11). This was clearly unexpected and highlights that the introduction of new technology must be carefully monitored and evaluated at every step to ensure that care is indeed improved and that there are no 'surprises'. Thus, while a handheld decision support system has been demonstrated to reduce antibiotic prescribing and patient length of stay in critical care (12), handheld computers used in clinical care have also (not surprisingly) been found to be contaminated with a variety of potential pathogens and could facilitate transmission in the health care setting (13). Of course, the proliferation of mobile and bedside clinical and pharmacy support systems, and the increasing provision of bedside computers for patient use as part of modern health care will raise similar concerns about the potential to harbour pathogens and antimicrobial-resistant organisms.

Equally unsettling, as we head down this road, will be questions regarding the vast databases of information that will be collected. Who owns the data in the electronic medical record or EHR system? Who has access to this information and for what purpose? How will the data be accessed for research? Who will safeguard the data and how? How will we protect the integrity of the patient-physician relationship? And finally, as health care regions invest in large electronic database systems and begin to accumulate large volumes of patient-related information, there is also a potential for the collection of large quantities of data regarding individual physician practice and performance. How do you compare with your peers? Who will have access to these data and for what purpose? While I do not generally subscribe to conspiracy theories and am not inclined to have an Orwellian Big Brother view of administration, the potential for these new technologies to be used for monitoring physician practice certainly exists.

I remember the day when a research project involved endless leafing through dusty issues of the Index Medicus searching for the relevant literature. Information for research or patient care is now at our fingertips and I am grateful for this. Modern IT and CDSS have the potential to provide data where you need it and when you need it to improve productivity and efficiency, and it should contribute to better and safer care. The promise is there, but not without peril and potential pitfalls. Infectious diseases clinicians and medical microbiologists need to provide input to ensure that these tools evolve to support and enhance our activities. This train is rolling, albeit slowly, and we best get on board to help navigate.

AMMI CANADA - CACMID ANNUAL CONFERENCE 2008: "Where Canada's Experts in Clinical Microbiology and Infectious Diseases Meet". Vancouver, February 27 to March 1, 2008. 


\section{REFERENCES}

1. Evans RS, Pestotnik SL, Classen DC, et al. A computer-assisted management program for antibiotics and other antiinfective agents. N Engl J Med 1998;338:232-8.

2. Canada Health Infoway. <http://www.infoway-inforoute.ca/en/ Home/home.aspx> (Version current at October 29, 2007).

3. Sherman M, Shafran S, Burak K, et al. Management of chronic hepatitis B: Consensus guidelines. Can J Gastroenterol 2007;21:5C-24C

4. Linder JA, Ma J, Bates DW, Middleton B, Stafford RS. Electronic health record use and the quality of ambulatory care in the United States. Arch Intern Med 2007;167:1400-5.

5. Garg AX, Adhikari NK, McDonald H, et al. Effects of computerized clinical decision support systems on practitioner performance and patient outcomes: A systematic review. JAMA 2005;293:1223-38.

6. Chaudry B, Wan J, Wu S, et al. Systematic review: Impact of health information technology on quality, efficiency, and costs of medical care. Ann Intern Med 2006;144:742-52.

7. Wears RL, Berg M. Computer technology and clinical work: Still waiting for Godot. JAMA 2005;293:1261-3.
8. Lapointe L, Rivard S. Getting physicians to accept new information technology: Insights from case studies. CMAJ 2006;174:1573-8

9. Zitner D. Physicians will happily adopt information technology. CMAJ 2006;174:1583-4.

10. Schurink CA, Lucas PJ, Hopelman IM, Bonten MJ. Computer-assisted decision support for the diagnosis and treatment of infectious diseases in intensive care units. Lancet Infect Dis 2005;5:305-12.

11. Sintchenko V, Iredell JR, Gilbert GL, Coiera. Handheld computer-based decision support reduces patient length of stay and antibiotic prescribing in critical care. J Am Med Inform Assoc 2005;12:398-402.

12. Koppel R, Metlay JP, Cohen A, et al. Role of computerized physician order entry systems in facilitating medication errors. JAMA 2005;293:1197-203.

13. Hassoun A, Vellozzi EM, Smith MA. Colonization of personal digital assistants carried by healthcare professionals. Infect Control Hosp Epidemiol 2004;25:1000-1. 


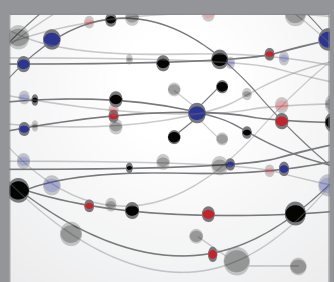

The Scientific World Journal
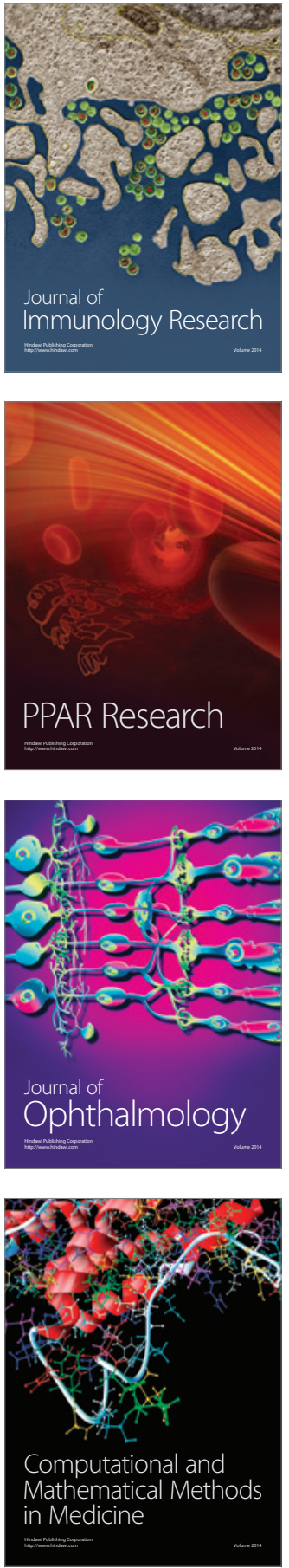

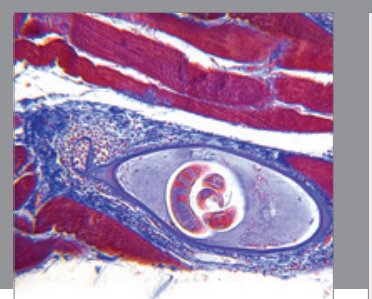

Gastroenterology Research and Practice

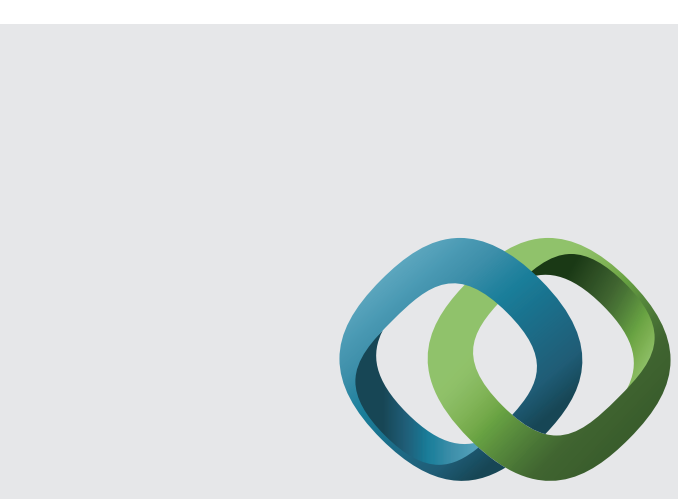

\section{Hindawi}

Submit your manuscripts at

http://www.hindawi.com
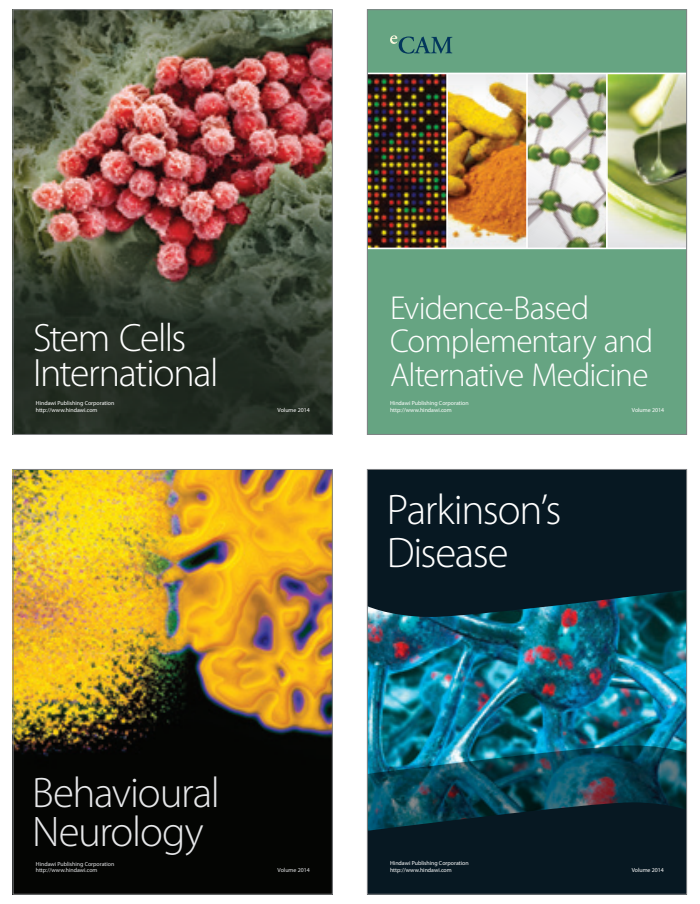
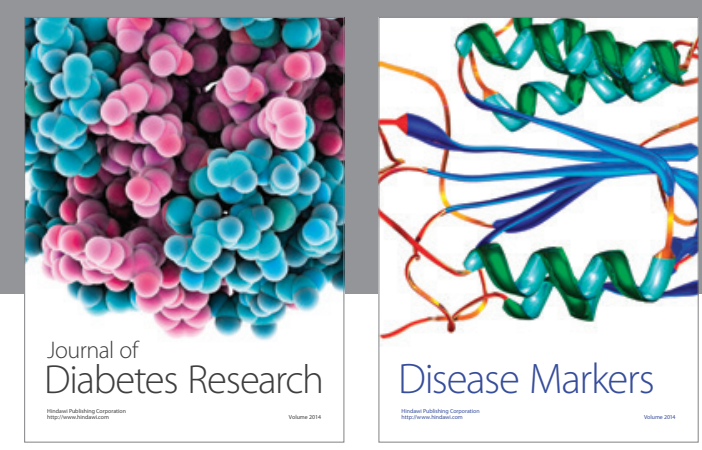

Disease Markers
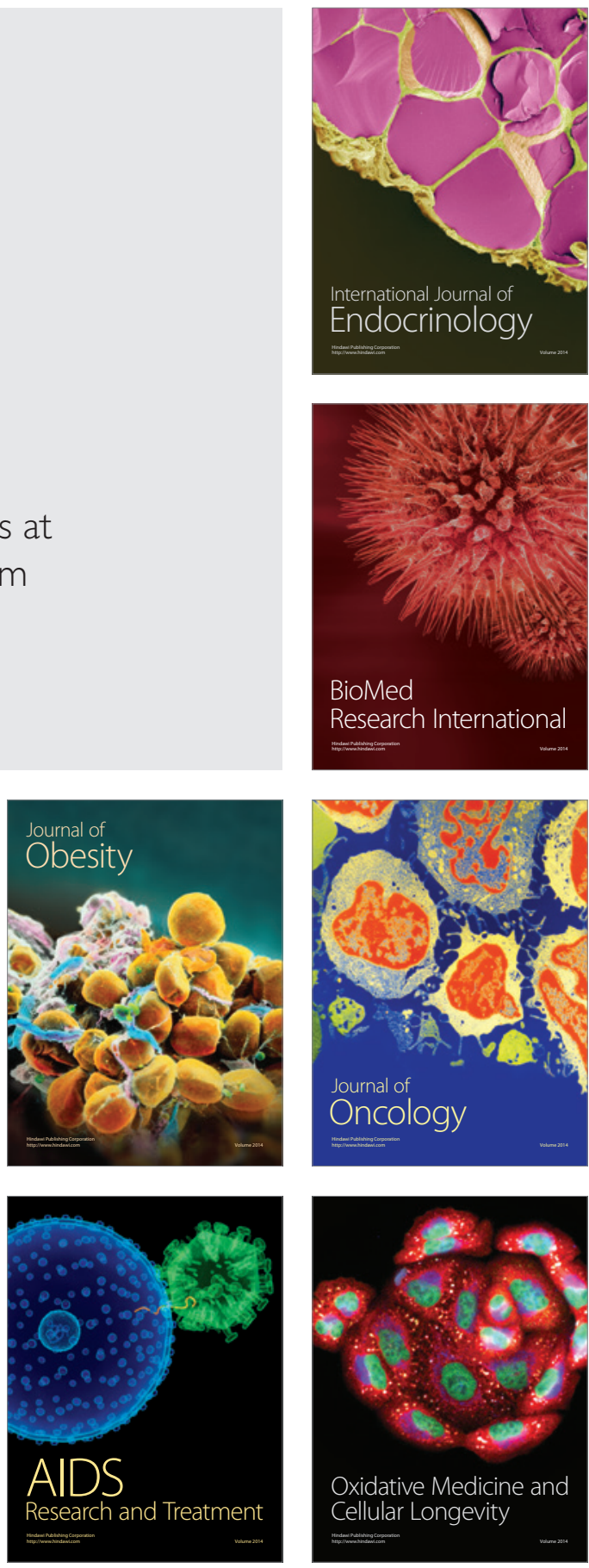